\title{
How Demotivated are EFL Teachers? A Kuwaiti College Perspective*
}

\author{
Hanan A. Taqi ${ }^{1}$, Ali A. Taqi ${ }^{2}$, Rahima S. Akbar ${ }^{1}$ \\ "This research was funded by the Public Authority for Applied Education and Training. \\ ${ }^{I}$ The English Department, College of Basic Education, Ardhyia, Kuwait \\ ${ }^{2}$ The Foundation and Administration of Education Department, College of Basic education, Ardhyia, Kuwait.
}

\begin{abstract}
Studies on factors that motivate language learners are extensive. They have looked at motivation from different perspectives such as teachers being motivators, curriculum, teaching context and the facilities available. However, it would also be interesting to know what the demotivating factors are, if any, not for EFL learners but for EFL instructors. The following study attempted to investigate the reasons behind the demotivation of language teachers in the College of Basic Education in Kuwait. The researchers designed a questionnaire, adapted from Warrington (2003), to be pilot tested, first, then distributed to approximately 46 teachers from the English Department and the English Language Unit from different ages, yearsin CBE and social status. The questionnaire aimed at covering all the aspects shown in the research questions below. In addition to thequestionnaire, random individual interviews were conducted to reportdirectly on the teachers' beliefs and needs as academics and higher educationinstructors, which also reflected on the research questions.

Keywords: Motivation, EFL, language, English, Demotivation, college, teachers, higher education
\end{abstract}

\section{Introduction}

Although teaching is a complicated --and often stressful-- job, it is also considered rewarding. The idea of "reward" is not related to economic fulfillment as much as it is related to an overall sense of accomplishment. A teacher is motivated to work when students show that they have learned, and when they are evaluated highly for being able deliver information properly. Motivation has been a major concern for Second language Acquisition (SLA) research.

At the early stages of SLA research, teaching was the focus of most research. For example, in 1969 at the International Association of Teachers of English as a Foreign Language (ATEFL), the core of research was teaching methodology, teacher training, and testing. In addition, studies in most cases fixated on teacher motivation, motivation strategies, and student-teacher motivation relationship (Roth, Assor, Maymon, \& Kaplan, 2007; Addison \&Brundrett, 2008)

While forty years later, the focus turned from teacher to learner; in 2006, the IATEFL conference discussion focused on anxiety, motivation, cultural awareness, collaborative learning, consciousness raising, and many other learner-related topics (Swan, 2009). It appeared that most studies focused largely on learner motivation and demotivation and rarely was teacher demotivation observed or analyzed in the EFL context. However, there are a few studies that investigated teacher demotivation (Doyle and Kim 1999; Connie 2000; Tiziava 2003; Zhang 2007; Brundrett 2008, Hettiarachchi 2010, Aydin 2012). Some of the main factors found in these studies to demotivate teachers were economic factors, administrative work, developmental problems, curriculum related problems, lack of facilities and material, heavy workload, and students' demotivation to learn. The following study investigates factors that demotivate EFL teachers in the College of Basic Education in Kuwait. The study commences with a detailed review of literature that displays valuable studies on demotivation. This would be followed by a list of the research questions and the methodology utilized to conduct the study which is three-folded. The results will be later analyzed via SPSS where significance, deviation and mean will be considered. Finally, the results will be discussed in the light of the literature review, and a conclusion will highlight the main findingsof this research.

It is hoped that in this study main demotivators for teachers in higher education are identified to be able to recommend solutions that would eliminate the existence of these demotivators, and hence improve the performance of teachers in higher education specifically, and teachers in all educational institutes generally.

\section{Literature Review}

Educators have long sought for accomplishing successful learning, whereby learners are enabled to reach out satisfactory standards of achievement. With teachers being at the core of the educational process, researchers have widely focused on enabling teachers to get their teaching job done at their highest potential.Such enabling mission may unlikely succeed without considering motivation as a central factor in any systematic reforming attempt of the teaching and learning processes. 
Thus, motivation has always been associated with the rate of success in any learning context. What is motivation, how does it affect learning, and how can educators raise the motivational levels of those who are involved in the learning process (learners and teachers)? These seem to be amongst educators' and researchers' concerns within teaching and learning.

Harmer (2005: 51) defines motivation as an active internal drive that pushes an individual to fulfil a certain goal at a satisfactory level of success. Such a drive is believed to be responsible for why we engage ourselves in a certain job, how long are we willing to sustain our efforts in that job, and how much effort are we willing to put into that job to get it done (Dornyei, 2001b). Within the field of second/foreign language learning, motivation has widely been identified as a key success factor (Gardner, 1985; Oxford \&Shearin, 1994; Ushioda, 1998 \& 2003), yet with a very big deal of controversy on how it affects the learning process. Ellis (2002) for example, questions whether motivation is causative (initiates learning), resultative (influences learning), intrinsic (driven by the individual's interests and needs), or extrinsic (driven by external sources).

The other flip of motivation is demotivation, defined as the process of losing motivation, due to extraneous factors. In this vein, some researchers stress that demotivation should be vividly distinguished from low motivation. Trang and Baldauf (2007) have therefore pinpointed the importance of examining demotivation as a separate entity rather than as part of the general motivational studies. This is not to say demotivation does not affect individual's motivational levels (Dornyei, 1990).

Most of the previous research within the educational arena has focused on how motivation, or the loss of motivation, amongst the learners may affect the learnability level of language learning. In this vein, Ushioda (1998) lists teaching methods, learning tasks, and course work load as major demotivational factors amongst the students. In Japan, the list extends to include, teachers' attitudes towards their students, teachers' personalities, teachers' language proficiency, alongside teaching methods, and the taught materials (Arai, 2004). Arab learners of English in Israel have stated teachers, learning groups, and textbooks as demotivating factors (Keblawi, 2005). Results of similar studies in Turkish universities have revealed class over-crowdedness to be the main source of demotivation amongst the students (Willos, 2011). Over-sized classes, as explained by the author, might annoy students, make class participation extremely embarrassing, and as a result, limit the students' confidence progression, let alone being a source of distress for teachers at the other end of the continuum. Geitenbeek (2011), on the other hand, finds large-sized classes demotivate teachers more than the students' attitude, since they lead to a quick teachers' burn-out, exhaustion, besides physical and mental straining.

When we looked into the literature on teachers' demotivation, we found that limited research has been mainly conducted on teachers' demotivational factors. It is crucial at this point to present that learning is a twoway process, in which a mandatory student-teacher interaction would always take place. Yet, teachers have been dropped out of the learning equation by most researchers in the field. Generally speaking, four major factors are identified as sources of both sides of the coin; motivation and demotivation. These include: exposure to new ideas, materials and equipment, quality of colleagues and supervisors, and the type of students they teach (Freeman \& Freeman, 1994). Amongst the few researchers whose studies investigate teachers' demotivation factors is Kiziltepe's study on demotivational factors among university teachers in Turkey (2008). According to the participating teachers' claims, the study categorises factors of demotivation across five main headings: students, economics, structural characteristics of the educational institutions, research and working atmosphere, with students being the main source of teachers' demotivation.

In Japan, a study conducted by Sugino (2010) on language teachers at Japanese universities classifies teachers' demotivation factors across four different dimensions: students' inappropriate attitudes (frequent cellphone in-class use, sleepiness and rebelliousness), curriculum problems (mainly inconsistent curriculum with no clear goal), class room conditions (especially poor audio-visual facilities, large-sized classes), and finally stressful working conditions of prolonged meetings, excessive paperwork and inadequate research time as the top stressful ones. More importantly, Menyhart (2008) claims that placing teachers in stressful atmosphere could be the most demotivating factor that may in many times hinder teachers from presenting their students with adequate teaching.

Crooks (1997) states imposed curriculums, mandatory textbooks, and top-down decision making as sore points for ESL/EFL teachers. EFL teachers across a variety of educational levels and setting in Mexico have presented students' negative attitudes towards learning the foreign language to be at the core of demotivating factors, followed by overloaded inflexible curriculums with unreasonable goals, and finally textbooks that tend to present the students with poor materials (Johnson, 2000).

In Palestine, Fattash (2013) explores demotivating factors amongst ESL university teachers. The study reveals somewhat differing aspects of demotivating factors amongst language instructors. Within such a special political condition in the country, teachers place more weight on adequate salary, rigid administrative regulations that hinders teachers' academic progress, and uncomfortable offices that lack privacy. At a lighter weight, comes large-sized classes, over loaded work, lack of teaching facilities, teachers' interrelations, and not enough access to research facilities. A similar economical demotivating factor has also been established in the 
Indonesian English private schools, in which local teachers of English are paid much less than their expatriate counterparts. According to the author of the study, such a discrepant payment has led to dissatisfaction in the job of teaching by both under-paid and over-paid teachers, a situation that has also affected teachers' mental wellbeing (Marai, 2002). Associated to the teachers' economic conditions, Auerbach (1991) describes 'alienation' as demotivating factor amongst teachers. This is when teachers, due to economic reasons, have to work in other jobs alongside teaching. Such teachers will live an alienated professional life as a result of being in limited contact with the overall educational setting.

In Kuwait, students' proficiency in English were claimed to be extremely low during the eight-year only English teaching curriculum in the country (Al-Mutawa, 1994). Recommendations were mostly in favour of implementing English teaching in primary schools in order to extend the students' exposure to the language for another four years. In the year 1993, the new curriculum has included English as a major teaching subject to children by the age of six, a very tough decision has been made in the hope of enhancing the abilities of Kuwait high school graduates in English. Whether the relatively recent implemented measure has really worked at the level of the students' attitudes towards learning English in the country, and the extent to which it has positively affected teachers of English motivational levels are two other issues that could be pinpointed in the current research. The current study will therefore attempt to investigate the reasons behind the demotivation of teachers in the College of Basic Education across various disciplines.

\subsection{The research question:}

What causes the CBEEFL teachers to be demotivated?

The question could be answered by focusing on the following sub-questions:

1. Are there students-related problems?

2. Are there appreciation-related problems?

3. Are there curriculum-related problems?

4. Are there work place-related problems?

5. Are there language-related problems?

\section{Methodology}

The study was conducted in Fall and Spring 2015/2016. The participants were 46 teachers from both the English Department and the English Language Unit in the College of Basic Education. The teachers were given a questionnaire adapted from Warrington's (2003) questionnaire that consists of 33 statements to be answered on a five point Lickert Scale, where "1" indicates "extremely demotivating" and "5" would indicate "doesn't demotivate". The questionnaire also consisted of three open-ended questions, and space for further comments associated with reason behind teacher demotivation.

Before the actual study was conduct, a pilot study was initiated in Spring 2014/2015. A sample of 10 EFL teachers participated in the pilot study, and the questionnaire Alpha-Bach was found to be 0.761, which indicated the appropriateness of the statements. The statements in the questionnaire covered five main aspects, found in the literature to be mostly affective in terms of motivation and demotivation; namely, students, facilities, working environment, reward and appreciation, and language.

After collecting the questionnaire papers, interviews with 12 participants were made to obtain detailed description of what mostly demotivates EFL teachers? And why the selected aspects seem to be more demotivating than others? The quantitative data was entered in SPSS and analysed in terms of frequency, significance, standard deviation and mean, with a concentration on the correlation between the statements and the independent variables of gender, age, years of experience, and degree.

\section{Results}

The data collection process contains three main categories: questionnaire statements, open-ended questions, and interviews.

\subsection{Questionnaire statements}

From the analysis of the data, the demotivation factors listed in the questionnaire varied in their level of importance; nonetheless, language seemed to be the most demotivating factor in the teachers' point of view. Students were also common demotivators in certain ways. To further illustrate, $56.5 \%$ of the participants felt highly demotivated when they sensed that the students were not interested. When investigating this point further, it was found that the youngest age group was the least demotivated by the students' interest $(m=3,20)$. In addition, a one-way ANOVA by years of experience showed that the participants with least experience were less demotivated by the students' interest, where $p \leq 0.01$ (significance is calculated at $p \leq 0.05$ ). The participating teachers also reflected high demotivation and demotivation when students were not prepared (25.8\% and $35.5 \%$ respectively). In a two way ANOVA by age and by years of experience, significance was found at $p=0.015$ due to the fact that the youngest group with the least experience seemed significantly less demotivated than the other 
groups. $71 \%$ of the teachers stated that when the students talk in class all the time, they become demotivated, while $80.7 \%$ are demotivated when the students misbehave. Surprisingly, in a one-way ANOVA by age, when the teachers where asked how demotivating it was when students use their mobile phones in class, the youngest age group was significantly most demotivated $(\mathrm{p} \leq 0.001)$. When the participants were asked how demotivated they felt when the students came without their books, $61.3 \%$ of the participants stated it was demotivating; however, the participants holding a master's degree were significantly most demotivated $(m=1.00)$. The majority of the participants were demotivated when the students misbehaved and when the students were poor academically. On the other hand, the participants reflected that students' discrimination towards their gender did not affect them. Chart (1) below displays the percentages of the answers to the statement "when the students discriminate between teachers according to their gender"

Chart (1) statement 8: when the students discriminate between teachers according to their gender

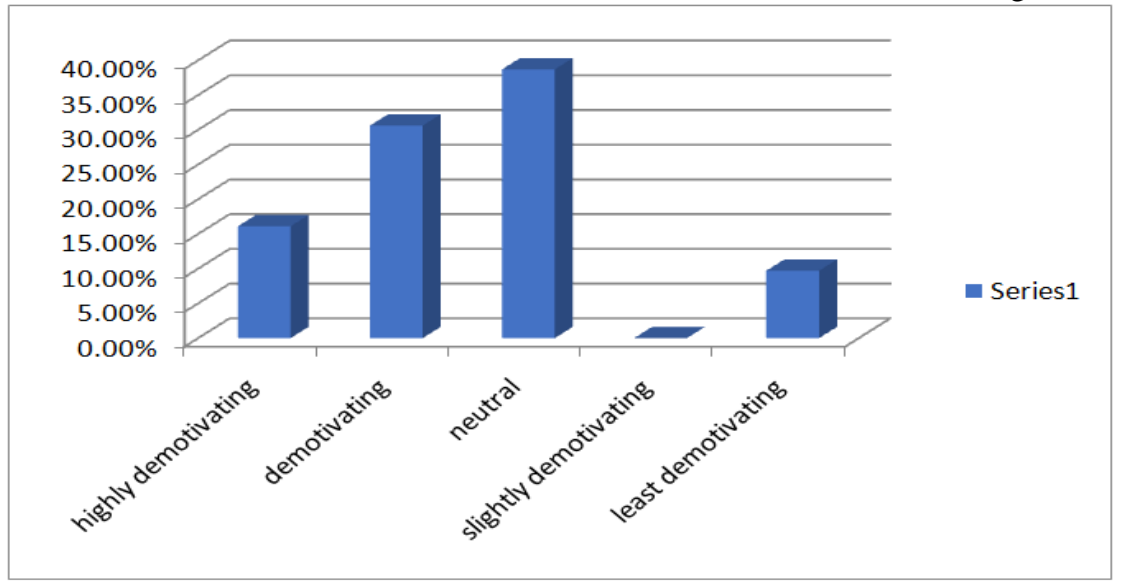

From Chart (1), it appears that discrimination is not as demotivating as other students-related factors. The second factor imbedded in the statements is concerned with facility related issues. In spite of the fact that most items under this factor reflected demotivation, the percentages reflect less demotivation than the studentrelated problems. Most participating teachers reflected that they were highly demotivated (41.9\%) when course books were not available. In a one-way ANOVA by years of experience, it appeared that the teachers with least experience were most demotivated where $\mathrm{p} \leq 0.01$. In addition, the youngest age group has reflected significantly less demotivation as $\mathrm{m}=3.00$. Furthermore, $37.1 \%$ of the participants were highly demotivated by the unavailability of audio-visual equipment as opposed to $4.8 \%$ who believed it was least demotivating. The majority of the participants were highly demotivated when there was noise outside the classroom and when the class size was very large (35.5\% and $40.3 \%$ respectively). In statement 13 , the participants were asked if they believed that the lack of suitable teaching material was a demotivating factor, the answers varied immensely. While $37.1 \%$ felt highly demotivated when suitable material was not available, $29 \%$ were neutral. A one-way ANOVA by years of experience shows significance as the second age group (36-45years old) were most demotivated. The majority of teachers reflected high demotivation when there was a fixed syllabus and they were not given space to be creative. In a one-way ANOVA by gender, male teachers appeared most demotivated as the mean average was 1.19 as opposed to the females' mean average which equalled 2.00 . The limited time of teaching was also considered a demotivator, as $64.4 \%$ stated they felt highly demotivated and demotivated when there was no time to teach.

The third factor investigated in this study was the work environment. The statements varied in their importance in this section, where over half of the participants were highly demotivated when there were a lot of staff meetings, and half of them did not feel demotivated when there was no course coordination. As the later item seemed to vary in response significantly, Chart (2) reflects the variation in the statement "when there is a lack of course coordination". In addition, $51.6 \%$ of the participants felt demotivated when the work goals were not clear. In a three-way ANOVA by age by years of experience by gender, high significance was found at $\mathrm{p} \leq 0.05$, as the male teachers and oldest age group with most experience was mostly demotivated by the lack of goals $(\mathrm{m}=1.00) .59 .7 \%$ of the participants are demotivated by the large amount of paper work. Having a lot of paper work is one of the demotivators of work for teachers. In a one-way ANOVA by gender, it appears that male teachers are more demotivated by paperwork than female teachers (where the mean for male teachers was 1.56 and for male teachers was 2.61). A two-way ANOVA by age by years of experience reflected significance of $p=\leq 0.01$. Heavy traffic driving to work was not found to be a major demotivator as $43.6 \%$ of the participants stated. On the other hand, $74.2 \%$ of the teachers found themselves demotivated when they did not have time to research. 
Chart (2) response to q18: when there is a lack of course coordination

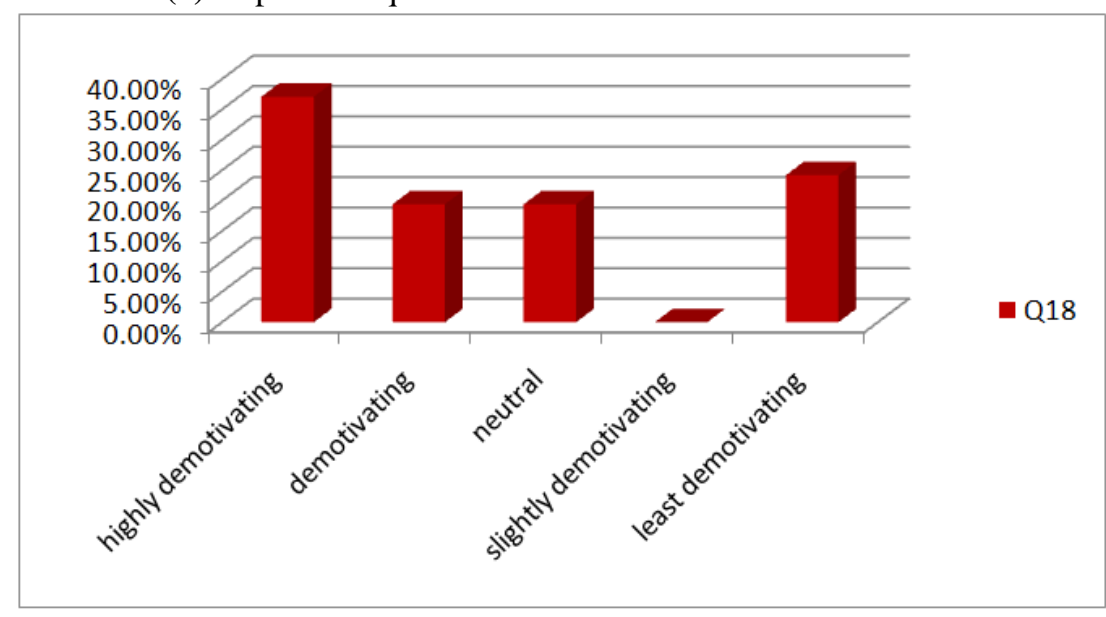

From Chart (2), it is clear that although the lack of coordination is demotivating to many participants, some participants did not feel it is an important factor.

The forth factor investigated was concerned with reward and appreciation. The majority of the participants reflected demotivation when they were discriminated against; the oldest group was significantly more demotivated by discrimination than the other age groups $(\mathrm{p} \leq 0.01)$. Many teachers believed that not being appreciated is a demotivator (35.5\%). $37.1 \%$ of the participants stated that students' evaluation did not cause demotivation, as opposed to $24.2 \%$ who consider low students' evaluation as a demotivator.

The final factor analysed in this study was language issues. From the data obtained, it appears that language problems were recognised as demotivators in general. $38.7 \%$ of the teachers stated that they become highly demotivated when the students do not like English as a language. In a one-way ANOVA by age, significance was found at $\mathrm{p}=0.027$. In addition, $43.5 \%$ of the participating teachers displayed demotivation when students did not speak English. When students were forced to study English, $43.5 \%$ of the teachers would be demotivated. When gender correlates with the statements "when students are forced to study English" significance was found at $\mathrm{p} \leq 0.01$.

Chart (3) Average percentage of factors demotivating EFL teachers

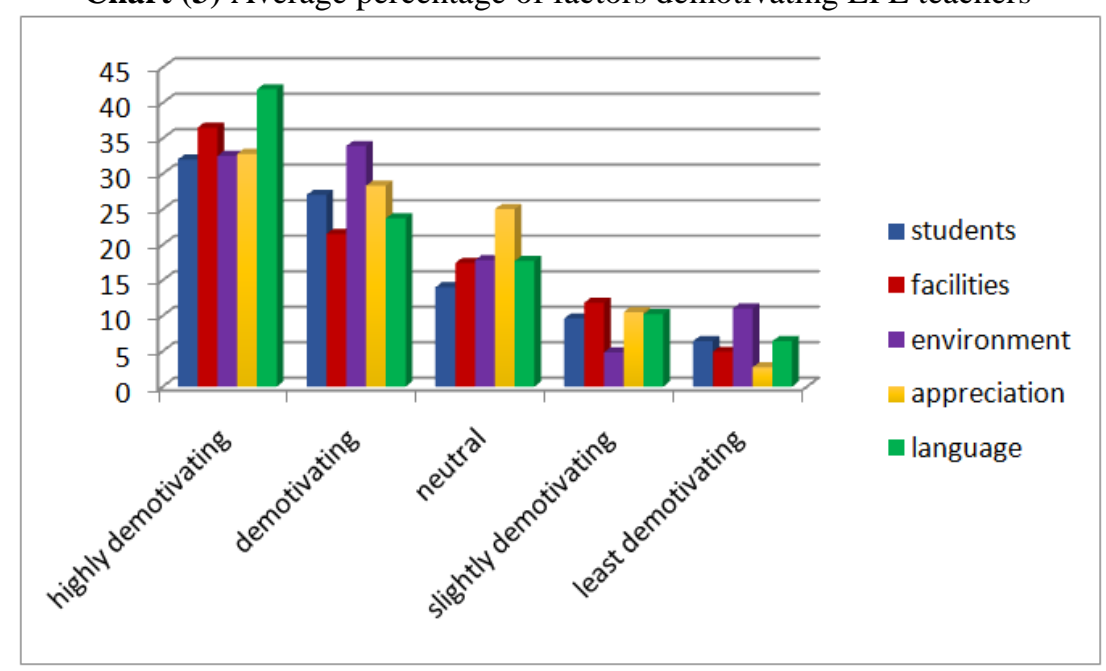

As can be seen in Chart (3), language could be the most demotivating factor affecting language teachers. In an attempt to identify the relationship between independent factors and demotivation of EFL teachers, the average response was calculated separately for gender, degree, age and years of experience. In terms of gender, female teachers were more demotivated than male teachers, and Ph.D. holders were more demotivated as well. The oldest age group, 56-65, appeared to be the most demotivated. Moreover, the teachers with 21 years of experience and more were the most demotivated and the teachers with 6-10 years of experience appeared to be the least demotivated. When the teachers were asked to rate the amount of demotivation on a scale of 1 to 10 , the majority of teachers chose " 8 " (25.8\%). Surprisingly, 14.5\% rated their demotivation " 10 ", and $6.5 \%$ rated their demotivation " 1 ". 


\subsection{Open-ended questions}

Teachers in the open questions were asked to add other demotivators, language teachers' demotivators, and if there were any other comments they would like to add. As for other demotivators, many teachers believed class size was very important; and if the class size was large, they would not be able to teach comfortably. Another factor mentioned by some teachers was the cleanliness of the classrooms. Some classes were left chaotic and untidy. Other factors mentioned, with less consistency, were students' ability to follow instructions, students missing exams, cultural barriers, lack of technical skills, absence of language labs on campus, no attention given by superiors, and constraints put on teachers' creativity.

The language-associated demotivators overlapped with the additional demotivators, where not being able to follow instructions in English and low grades were the most common factors mentioned. In addition, not being able to read exam questions properly or discuss in English were also mentioned as factors that would motivate them as EFL teachers. Finally, many teachers were disappointed that many students had negative attitude towards language learning.

In the other comment section, many teachers asked to read the findings of the research, as they were curious as to how other teachers felt towards demotivating factors in the EFL context. One teacher stated that she is highly demotivated because after teaching for 7 years, she feels that the institute does not have a clear educational policy and vision. Another teacher added that the policy does not suit the modern world, for example, the students need to learn how to use technology in education yet hardly any technological facilities are available in college for EFL students and teachers.

\subsection{The Interviews}

Out of the 46 teachers participating by replying to the statements in the questionnaire, 12 teachers were interviewed. Only one of the 12 teachers stated that he was completely motivated to work, and does not find these factors demotivating at all. He added that every demotivating factor could be motivating if looked at from a different angle.

On the other hand, all the other EFL teachers interviewed reflected high demotivation for many reasons, most of which were presented in the questionnaire. Most participants in the interview stated that the teaching context in general was demotivating because the situation was not improving. For instance, some teachers stated that the lack of a language lab is a need that the teachers have been pursuing for years. "How important is our job?" asked a participant, adding that the importance of EFL teachers was reflected in what they are provided by administration in of facilities and material to deliver their part of the job perfectly. The more they teach without a language lab, the more demotivated they become. Another example is students' language abilities. Every term, students who join the English Department seem to have less English language competency than the term before, many of which were obliged to study English but were not interested in learning the language. Many students bluntly state that they want to change their major, but do not have the appropriate GPA. All the teachers interviewed believed that the students have the tendency of demotivating teachers, and many believed that students' negligence was a major demotivator.

It appears from the interview, that many teachers feel that they are not receiving enough training to follow up on the latest in EFL teaching and learning processes. Many teachers stated they would like to research and train in the EFL field, yet the time and the money was not available for such research and training. Some teachers were surprised that employees with administrative work receive periodic training courses, and EFL teachers do not. Some teachers have never received any form of teacher training, and learned their teaching techniques from trial and error. Teaching courses were not offered to the teachers of the English Department, and teachers in the Language Centre are not sure if there is a law that prevents language teachers from enrolling in a training course during the term.

Most teachers in the interview felt that EFL classes in CBE did not belong to the $21^{\text {st }}$ century. One teacher reflected "I try to show them a movie but there is no internet". Another teacher stated that she was highly demotivated when the data-show projector was broken, and no one would fix it for months! Some teachers stated that technology would help in time management, and since there are a lot of holidays, the use of technology might help them cope with the limitation of teaching hours. One teacher commented when asked about technology "we have a smart board without internet... how does that work?" Does the lack of technology demotivate you? Yes! Was a common reply, and many believed it is a major factor which would cause demotivation.

Finally, when the participants were asked if they are currently demotivated, 10 of them stated that they are, and most participants stated that if they were asked to change their job or place of work they would seriously consider that option. "Nothing seems to improve, nothing is getting better; yes, I'm highly demotivated at the moment", a comment from one of the teachers that says it all. 


\section{Discussion}

The current study investigates the degree of demotivation and the factors causing demotivation. As previous studies have shown, EFL teacher demotivation is associated with the work environment, students, facilities and curriculum (Crooks, 1997; Menyhart, 2008; Johnson, 2000; Fattash, 2013, among others).

The first factor, and the most demotivating one, was students. This factor is divided into two points "students' demotivation" and "language proficiency". It appears from the results that the demotivation of students is a main cause of the demotivation of teachers. Most teacher participants believed that when students did not have the will to learn in general, and to learn the language more specifically, they are demotivated. This finding goes hand in hand with Johnson's (2000) finding which shows that students' negative attitudes towards learning the foreign language is the core of demotivating factors.

In addition, Freeman \& Freeman (1994) found in their study that the "type of students" affect teacher motivation. Hence, the lack of interest in learning the language, negligence and the weak language abilities (language proficiency that hinders understanding) demotivate teachers more than any other factor. In this study, some teachers faced students who frankly stated their unwillingness to work, and their hope to pass the course which they "don't like". When the core of the classroom depends on the "type of students", and their type is "lacking interest", the EFL teacher by nature loses interest and is cornered into demotivation.

The second demotivating factor is the teaching environment, which includes meetings and paperwork, coordination, classroom size, availability of textbooks and tidiness of classroom. Most language teachers were frustrated with large amounts of students in classrooms. They believed it was impossible to learn a language without individual attention which could not be offered in large sized classrooms. Willos (2011) found that oversized classrooms annoy students, make class participation extremely embarrassing, and as a result, limit the students' confidence progression. During the interview, some teachers expressed their disappointment when they enter a messy classroom, with chairs scattered all around. Constant tidying of classrooms is a hassle and a waste of time, something teachers find demotivating. Freeman \& Freeman (1994) showed that in Mandated Policies, realistic class size is emphasized, and the importance of size, cleanliness, acoustics and other physical qualities of the classroom is important to the teachers. As teachers usually work two or more hours in English classrooms, they expect certain conditions to be met to feel more satisfied in their work space.

The third demotivating category is connected to the facilities available. The participating EFL teachers are highly aware of the need for audio-video equipment, internet and a language lab. The teachers emphasized the importance of utilizing technology, stating it would help the class become student-centered and makes learning more interesting and fun. Some teachers emphasized the importance of technology as a time management tool. They believed that the use of technology would save them valuable teaching time. Hence, when the teachers weredenied access because extra learning aids were not provided, they believed they were not capable of accomplishing their job satisfactorily and they were demotivated.

The final category which appeared to be the least demotivating (yet is generally demotivating) is appreciation and reward. A good relationship with co-workers and the appreciation of superiors is of high importance in the EFL context. Crooks (1997) states that top-down decision making are core issues for ESL/EFL teachers. Moreover, Freeman \& Freeman (1994) found that having a friendly and professional work environment where colleagues are interested in professional development and help each other was a necessary factor in the EFL teacher's job. As found in this study, Freeman \& Freeman (1994) found that "apathetic" colleagues are a cause of demotivation. The participants of the current study believed that unappreciative supervisors and colleagues demotivate them.

It is worth noting that economic issues have reflected very little importance along with the transportation and commuting problems. Although some teachers believed not being paid on time could be stressful, unlike the findings in Fattash (2013), the salary in this study appeared to be the least demotivating factor. In spite of spending very long hours commuting in heavy traffic, EFL teachers generally did not feel that time spent commuting was a demotivator.

Finally, the teachers participating were found to be demotivated in general, where the mean of their own rating of their demotivation was 6.73 (on a scale from 1-10). The reasons behind their demotivation are listed in the factors above, and require immediate attention.

\section{Conclusion}

Demotivation is an issue that must be addressed in the EFL higher education realm. This study attempted to investigate demotivating factors that affected EFL teachers in CBE in Kuwait. 46 teachers from the English Department and the Language unit participated in this study. The data was collected through a questionnaire with open and close ended questions and statements, and interviews conducted with 12 teachers.

It was found that many teachers are demotivated in general. The most demotivating factor appeared to be the students. More specifically, the students' lack of interest and poor English language proficiency are major demotivators. The work environment is the second demotivating factor. This factor included lack of learning 
facilities, unclean classrooms, and most importantly, over-sized language classrooms. The third factor affecting teachers' demotivation was the availability of facilities such as the internet and audio-visuals. Finally, appreciation, while not as demotivating as the above three factors, was found to be demotivating. Nevertheless, this factor included cooperation with colleagues, and recognition by superiors.

The findings of this study are quite alarming, since many teachers have stated that they are highly demotivated. The researchers recommend a complete evaluation of the current system of admission and teaching in the English Department and Language Unit in CBE. The type of students accepted should be evaluated, and only students willing to learn English and have interest should be admitted. Language classrooms should never be oversized, it makes learning a hectic task, and participation an embarrassing mission. Furthermore, classrooms should be equipped sufficiently for language teaching according to international standards and EFL technological needs found in different studies.

Once the learning environment is evaluated and amended to become suitable for both students and teachers, colleagues will become cooperative and friendly by default. Teaching and learning is a never-ending cycle. When teachers are demotivated, learners become demotivated... and the cycle is endless. Educational institutions should periodically investigate the four factors (students, environment, facilities and appreciation) to assure constant motivation of teachers and learners. A happy learning environment produces happy creative teachers that are willing to push themselves beyond their limits, which results in more interested and creative learners.

\section{References}

[1]. Auerbach, E. R. (1991). Politics, Pedagogy, and Professionalism: Challenging Marginalization in ESL. College ESL, 1(1), 1-9.

[2]. Al- Mutawa, N. ( 1994 ) Factors influencing English language teaching and learning in the secondary schools in Kuwait. Educational Sciences, Cairo University, 1(2), 3363 .

[3]. Crookes, G. (1997). What influences what and how second language teachers teach? Modern Language Journal, 81, 67-79.

[4]. Dörnyei, Z. (1990). Conceptualizing motivation in foreign language learning. Language Learning, 40, 46-78. DOI: 10.1111/j.14671770.1990.tb00954.x

[5]. Dornyei, Z. (2001a) Teaching and Researching Motivation. Harlow: Longman.

[6]. Dornyei, Z. (2001b) Motivational Strategies in the Language Classroom. Cambridge University Press.

[7]. Dornyei, Z. (2001c) New themes and approaches in second language motivation research. Annual

[8]. Review of Applied Linguistics 21, 4359

[9]. Ellis, R. (2002). The place of grammar instruction in the second/ foreign language curriculum. In E. Hinkel \& S. Fotos (Eds.), New perspectives on grammar teaching in second language classrooms (pp. 17-34). Mahwah, N.J.: Lawrence Erlbaum.

[10]. Fattash, M. M. (2013). Demotivating factors of university ESL teachers. International Journal of Humanities and Social Science, 3 (19), 125- 132

[11]. Freeman, D. \& Freeman, Y. (1994). Between Worlds: Access to Second Language Acquisition. NH: Heinemann.

[12]. Gardner, R.C. (1985) Social Psychology and Second Language Learning: The Role of Attitudes and Motivation. London: Edward Arnold.

[13]. Geitenbeck, J. (2011). Effects of overcrowded classrooms. Retrieved 2012 from: http://www.helium.com

[14]. Harmer, J. (2005). The Practice of English Language Teaching (3rd ed.). Essex: Longman.

[15]. Johnson, C. R. (2000). Factors influencing motivation and de-motivation of Mexican EFL teachers. Paper presented at the annual meeting of Teachers of English to Speakers of Other Languages, Vancouver, Canada.

[16]. Keblawi, F 2005. Demotivation Among Arab Learners of English in Israel. The Second International Online Conference on Second and Foreign Language Teaching and Research. September 16-18, 2005. The United States. Reading Matrix Inc.

[17]. Kiziltepe, Z. (2008). Motivation and demotivation of university teachers. Taylor and Francis, Ltd. Philadelphia, PA

[18]. Marai, L. (2002). Double de-motivation and negative social affect among teachers in Indonesia. South Pacific Journal of Psychology, 14(1), 1-7.

[19]. Menyhárt A. (2008).Teachers or lecturers? The motivational profile of university teachers of English. WoPaLP, 2, 119-137

[20]. Oxford, R., \&Shearin, J. (1994). Language learning motivation: Expanding the theoretical framework. Modern Language Journal, $78(1), 12-28$

[21]. Swan, M. (2009). We do need methods. Cook, V. \& Wei, L. (Eds.). Contemporary applied linguistics: Language teaching and learning, vol. 1. (pp. 117-136). London: Continuum International Publishing Group.

[22]. Sugino, T.\& (2010). "Teacher demotivational factors in the Japanese language teaching context",in Procedia( \&( Social( and( Behavioral( Sciences, 3:\& 216,226

[23]. Trang, T. T. \& T., Baldauf, R. B. (2007). Demotivation: Understanding resistance to English language learning- the case of Vietnamese students. The Journal of Asia TEFL, 4(1), 79-105.

[24]. Ushioda, E. (1998). Effective motivational thinking: A cognitive theoretical approach to the study of language learning motivation. In A. Alcon, \& V. Codina (Eds.), Current issues in English language methodology, 77.89. Castello de la Plana, Spain: Publicacions de la UniversitatJaume I.

[25]. Ushioda, E. (2003) Learner autonomy in the foreign language classroom. In D. Little, J. Ridley and E. Ushioda. (eds) Motivation as a Socially Mediated Process (pp. 90101). Dublin: Authentik.

[26]. Warrington, M. \& Younger, M. (2003) 'We decided to give it a twirl': Single-Sex Teaching in English Comprehensive Schools, Gender and Education, 15, pp.339-350

[27]. Willows, M. (2011). Effect of overcrowded classrooms. Retrieved 2012 from: http://www.helium.com 